\title{
The Use and Know-how of ICT-technology in Different Age Groups
}

\author{
Leena Korpinen ${ }^{1}$, Rauno Pääkkönen ${ }^{2}$ and Fabriziomaria Gobba ${ }^{3}$ \\ ${ }^{I}$ Environmental Health, Tampere University of Technology, Tampere, Finland \\ ${ }^{2}$ Finnish Institute of Occupational Health, Tampere, Finland \\ ${ }^{3}$ Department of Public Health Sciences, University of Modena and Reggio Emilia, Modena, Italy
}

\begin{abstract}
Keywords: $\quad$ ICT, Computers, Age.
Abstract: When developing various ICT solutions to support people's well-being, the systems are quite often based on the use of computers or smart phones. However, in different age groups, the skills to use ICT can vary; therefore, not all people can use new technical systems. The aim of this paper was to investigate the selfreported use and know-how of the ICT-technology in different age groups and using the answers to the following questions: 'how often do you use a desktop computer at leisure?' and 'how well do you know the desktop computer?'. The study was carried out as a cross-sectional study by posting the questionnaire to 15,000 working-age Finns. To the question 'how well do you know the desktop computer?', $22 \%$ of the 20 30 age group answered 'very well' and $19.1 \%$ of the $31-40$ age group also replied 'very well'. In the 41-50 age group, the value was $15.7 \%$, and in the age group 51-60, the value was $10.6 \%$. In the future, when new well-being ICT technology is developed, it is important to take into account that older people do not know as much about ICT as younger people.
\end{abstract}

\section{INTRODUCTION}

With the advance of well-being ICT technology, a variety of new devices or internet solutions have entered the market. The use of computers and other mobile internet or communication devices has increased. For example, according to the Finnish Statistics Office (2008), in 2006, the percentages of computer users among people aged 18-64 years was $100 \%$ in upper-level, white-collar workers and students. According to the Finnish statistical office (in spring 2007), $79 \%$ of aged 15 to 74 used the internet. However, only $40 \%$ of people over the age of 60 used the internet.

The Tampere University of Technology (TUT) has investigated the health effects of new technical equipment using a questionnaire sent to 15,000 working-age Finns. The questionnaire included questions on the familiarity and usage of new technical devices, prevalence of physical and mental symptoms, accidents associated with mobile phone use and an open-ended question on health and new technology (Korpinen et al., 2009).

Our earlier article "Self-reported use of ICT (Information and communication technology) uptake in 2002 and discomfort amongst Finns aged 45-66" presented that less than $30 \%$ of Finland's middleaged population use daily desktop computers at leisure. The use of new technical equipment among the group of people who are outside working life was lower than the people's usage in general $(4,9 \%$ of women outside working life and $13.1 \%$ of men outside workig life). (Korpinen and Pääkkönen, 2010).

The amount of daily internet use was $17.5 \%$ in all data of Finns aged 45-66, 4.9\% of women outside working life and $8.0 \%$ of men outside working life. However, $72 \%$ of all Finns aged $45-66$ used mobile phones on a daily basis, and $59.4 \%$ of female respondents outside working life and $60.3 \%$ of male respondents outside working life used mobile phones daily. (Korpinen and Pääkkönen, 2010).

The aim of this paper was to investigate the selfreported use of the ICT-technology in different age groups and using the answers to the questions 'how often do you use a desktop computer at leisure?' and "how well do you know the desktop computer?". In addition, some self-reported symptom's influence on the answers will be studied. 


\section{METHODS}

\subsection{Study Population and Questionnaire}

The cross-sectional study focused on the workingage population, and the questionnaire was sent to 15,000 Finns between the ages of 18 and 65. The names and addresses of the participants were obtained as a random sample from the Finnish Population Register Centre. The study design was approved by the Ethical Committee of Pirkanmaa Health District, Finland (decision R02099).

The questionnaire included six sections: (1) background information, such as age, gender, marital status, education, occupation, and home county; (2) the familiarity and use of given technical devices at leisure and at work; (3) physical loading and ergonomics; (4) psychological welfare; (5) accidents and close-call situations at leisure or at work and (6) an open-ended question regarding 'other observations concerning technology and health'. The details of the questionnaire have been published earlier (Korpinen et al., 2009).

\subsection{Analyses}

The statistical analysis was performed using IBM SPSS Statistics versions 22 software. Age groups were classified as under 20, 21-30, 31-40, 41-50, $51-60$, and over 60 . For the analysis, we took group 2 (21-30), group 3 (31-40), group 4 (41-50), and group 5 (51-60). We analyzed the answer percentages to the questions: a) How often do you use the desktop computer at leisure? (choices: (0) cannot say, (1) not at all, (2) less than monthly, (3) monthly, (4) weekly, and (5) daily); b) How well do you know the desktop computer? (choices: (0) cannot say, (1) very poorly, (2) pretty poorly, (3) moderately, (4) pretty well, (5) very well).

The options for question 16) 'Have you suffered a) sleeping disorders/disturbances, b) depression, during the last 12 months?' was classified so that answers cannot say, not at all and sometimes were coded 0 (no symptoms), and quite often, often and very often were 1 (symptoms).

To compare differences between the age groups we used independent samples Mann-Whitney U-test analyses.

\section{RESULTS}

A total of 6,121 responses $(3,486$ women and 2,625 men) were received, and the average age of the respondents was 41 years old. The amount of the responses to the different age groups were: in the group 2 (21-30) 1229 answers, in the group 3 (3140) 1305 answers, in the group 4 (41-50) 1375 answers and in the group 5 (51-60) 1479 answers.

Figure 1 shows the answers of all participants to the question 'how often do you use a desktop computer at leisure?' and Figure 2 shows the answers to the question 'how well do you know the desktop computer?'

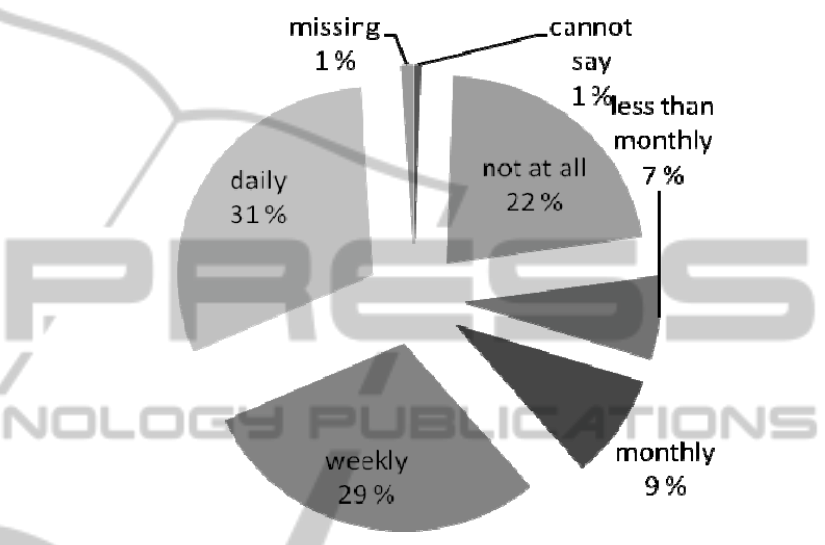

Figure 1: The answers for the question 'how often do you use a desktop computer at leisure?'.

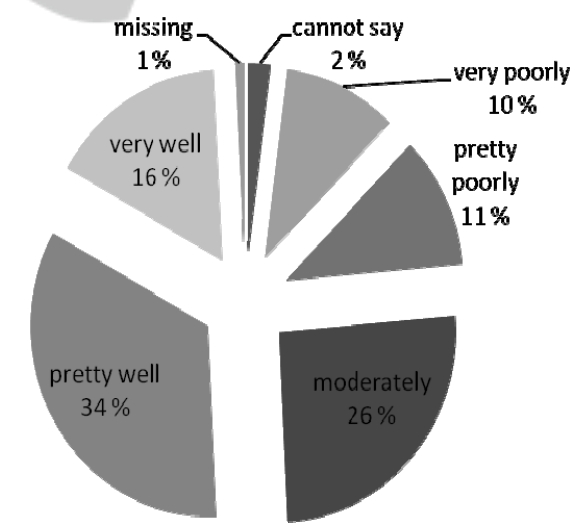

Figure 2: The answers for the question 'how well do you know the desktop computer?'.

Figure 3 shows results for the question 'how well do you know the desktop computer?' in different occupational groups.

Figure 3 shows that occupational groups "homework, students" and "upper-level white collar workers" know the desktop computers best. Altogether, $11 \%$ of the participants outside working life know desktop computers very well and $29 \%$ of them know it pretty well (Figure 4). 


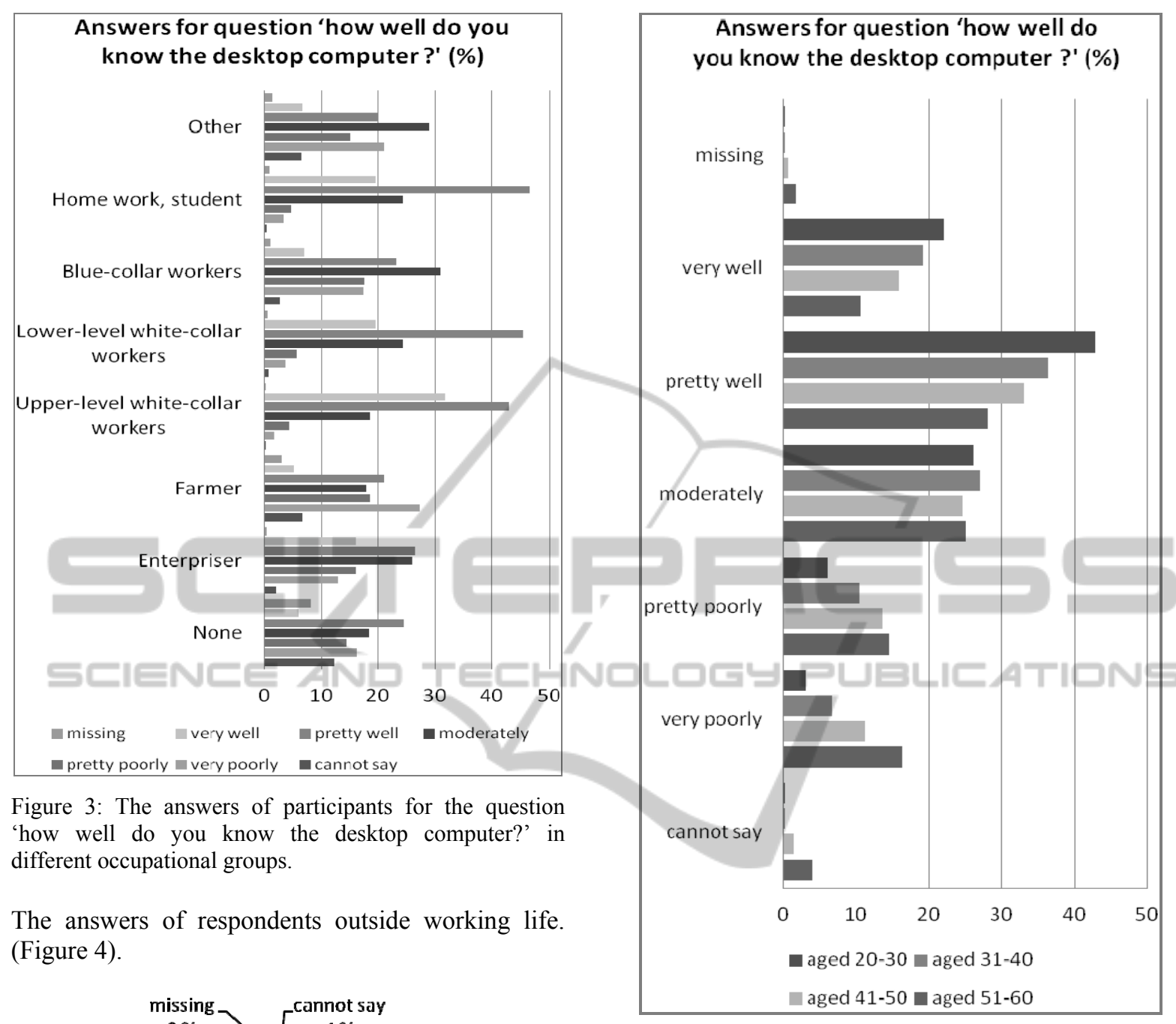

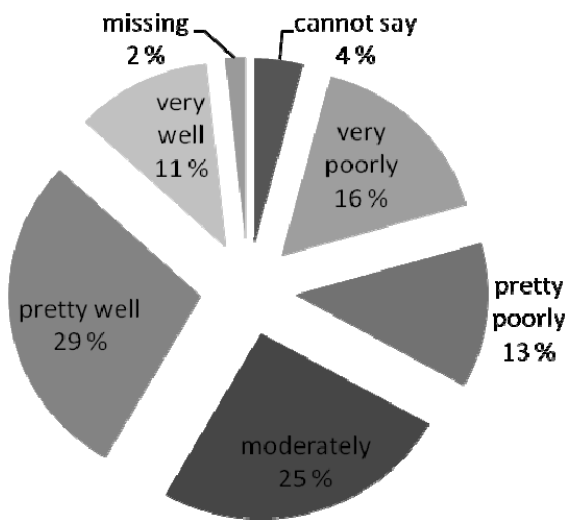

Figure 4: The answers of participants outside working life for the question 'how well do you know the desktop computer?'.

Figure 5 shows the answers to the question 'how well do you know the desktop computer?' in different age groups.
Figure 5: the answers to the question 'how well do you know the desktop computer?' in different age groups.

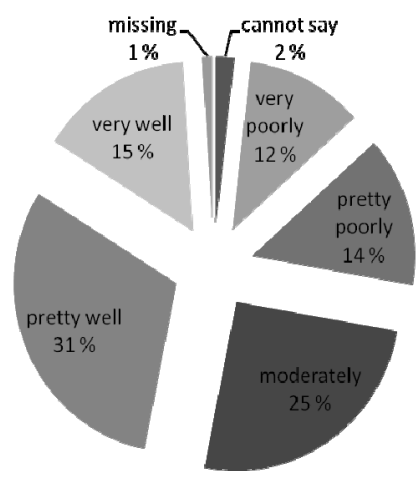

Figure 6: the answers of participants who self-reported sleeping disorders / disturbances to the question 'how well do you know the desktop computer?'.

Figures 6 and 7 show the answers of participants who self-reported sleeping disorders/ disturbances or 
depression, during the last 12 months, to the question 'how well do you know the desktop computer?' Figures 8 and 9 show the answers of participants who did not report sleeping disorders / disturbances or depression, during the last 12 months.

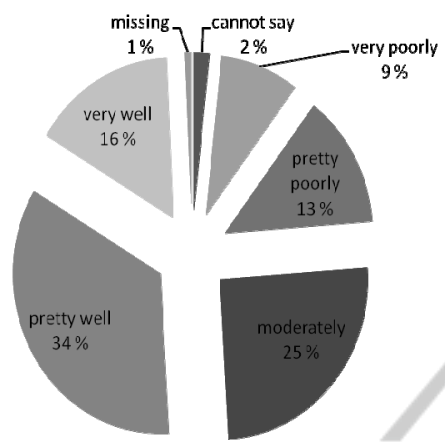

Figure 7: the answers of participants who self-reported depression to the question 'how well do you know the desktop computer?'.

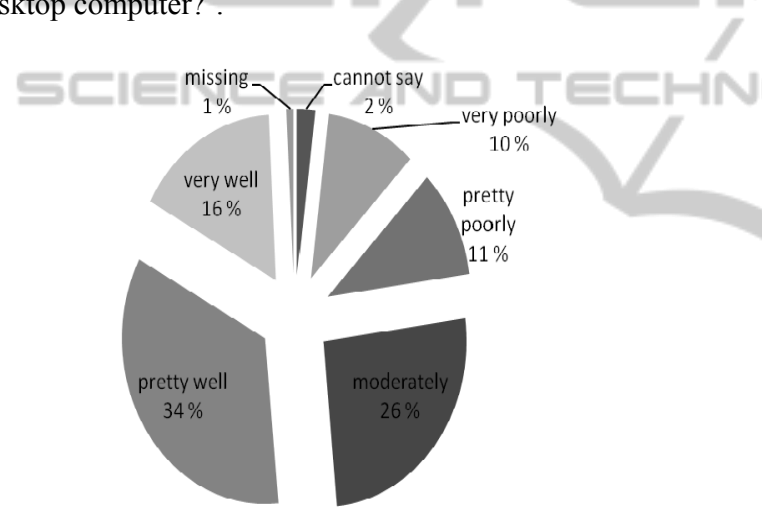

Figure 8: the answers of participants who did not selfreport sleeping disorders / disturbances to the question 'how well do you know the desktop computer?'.

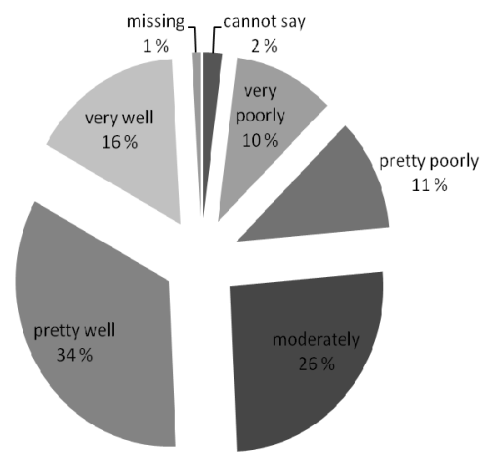

Figure 9: the answers of participants who did not selfreport depression to the question 'how well do you know the desktop computer?'.

To the question 'how well do you know the desktop computer?', $22 \%$ of the age group 20-30 answered very well and $19.1 \%$ of the $31-40$ age group also answered very well. In the age group 41 50 , the value was $15.7 \%$ and in the $51-60$ age group, the value was $10.6 \%$.

Table 1 shows the results of the comparison between the different age groups using the answers to the question 'how often do you use a desktop computer at leisure?' (with independent samples Mann-Whitney U-test analyses).

Table 1: The results of the comparison between the different age groups using the answer to the question 'how often do you use a desktop computer at leisure?'.

\begin{tabular}{|c|c|}
\hline $\begin{array}{c}\text { Comparison groups with } \\
\text { Mann-Whitney U-test }\end{array}$ & Asymp. Sig.(2-tailed) \\
\hline Group 2 - Group 5 & $<0.001^{*}$ \\
\hline Group 3 - Group 5 & $<0.001^{*}$ \\
\hline Group 4 - Group 5 & $<0.001^{*}$ \\
\hline Group 2 - Group 4 & $<0.001^{*}$ \\
\hline Group 2 - Group 3 & $<0.001^{*}$ \\
\hline Group 3 - Group 4 & 0.060 \\
\hline * significant at p $<0.05$ & A
\end{tabular}

In table 1, there were significant differences between almost all age groups. Younger persons used more a computer at leisure than older persons.

Table 2 shows the results of the comparison between the different age groups using the answer to the question 'How well do you know the desktop computer?' (with independent samples MannWhitney U-test analyses).

Table 2: The results of the comparison between the different age groups using the answer to the question 'How well do you know the desktop computer?'.

\begin{tabular}{|c|c|}
\hline $\begin{array}{c}\text { Comparison groups with } \\
\text { Mann-Whitney U-test }\end{array}$ & Asymp. Sig.(2-tailed) \\
\hline Group 2 - Group 5 & $<0.001^{*}$ \\
\hline Group 3 - Group 5 & $<0.001^{*}$ \\
\hline Group 4 - Group 5 & $<0.001^{*}$ \\
\hline Group 2 - Group 4 & $<0.001^{*}$ \\
\hline Group 2 - Group 3 & $<0.001^{*}$ \\
\hline Group 3 - Group 4 & $<0.001^{*}$ \\
\hline * significant at p $<0.05$ &
\end{tabular}

In table 2, there were significant differences between all age groups so that younger persons know better a computer than older persons.

\section{DISCUSSION}

In this questionnaire study, the population was 15,000 working-age persons in Finland, and the amount of responses was 6,121 (41\%) (Korpinen et 
al. 2009). The data was quite large. However the non-response rate was over $50 \%$. The main focuses of the questionnaire were the use of the new technical units (e.g., desktop computers, portable computers, hand-held computers, communicators, internet, mobile phones, electronic marketplaces/ commerce and teletext) and physical/mental symptoms. We asked many questions of the participants' know-how regarding new technology. Therefore, we cannot make any strong conclusions from the data. In addition, this questionnaire data is about 10 years old, which is a long time in consumer technology. For example, the use of the internet has increased in all age groups. However, there can still be differences between different groups. Typically, young persons are more active in using new technology.

In general, about $30 \%$ of all participants used desktop computers daily, and $16 \%$ of all know the desktop computer very well. Figures 3-8 show that younger persons and persons who typically use computers at work know desktop computers better than others. This is easy to understand. However, it is important to remember, when new well-being technology or technology as part of treatment will be developed, that older persons and persons outside of working life are not always experts in the use of technology. On the other side, older persons are typically persons who need medical treatment and the technology developed for the well-being area. Figures 6-9 show that persons who self-reported depression or sleep disorders / disturbances are as familiar as others with desktop computers and show in practise no difference. So those symptoms are not relevant in the development of the new well-being technology.

\section{CONCLUSIONS}

The daily use of desktop computers of all participants was about $30 \%$ at leisure in all the data, and $16 \%$ know desktop computers very well. To the question 'how well do you know the desktop computer?', $22 \%$ of the age group 20-30 answered very well and $19.1 \%$ of the age group $31-40$ also answered very well. In age group 41-50, the value was $15.7 \%$, and in the $51-60$ age group, the value was $10.6 \%$. Altogether, $11 \%$ of the participants outside working life know desktop computers very well. In the future, it is important to take into account that older people do not know as much about ICT as younger people, and it can influence the use of the new well-being technology.

\section{ACKNOWLEDGEMENTS}

The assistance of the staff (Noomi Suuronen, Jari Latva-Teikari and Riitta Lehtelä) of the Environmental Health group, Tampere University of Technology, is gratefully acknowledged.

\section{REFERENCES}

Finnish Statistics office, 2008. 2. Still more adult use computers. (in Finnish) http:// www.stat.fi/til/aku/ 2006/03/aku_2006_03_2008-06-03_kat_002_fi.html [Last updated 3 June 2008]

Finnish Statistics office, 2007. Internet used by 79 per cent of the population at the beginning of 2007 . http://www.tilastokeskus.fi/til/sutivi/2007/sutivi_2007 2007-09-28_tie_001_en.html [Last updated 28. September 2007].

Korpinen, L., Suuronen, N., Latva-Teikari, J., Pääkkönen, R., 2009. Questionnaire on the health effects of new technical equipment. International Journal of Industrial, Ergonomics 39, 105-114.

Korpinen, L., Pääkkönen, R., 2010. Self-reported use of ICT (Information and communication technology) uptake in 2002 and discomfort amongst Finns aged 45-66, Applied Ergonomics 42, 85-90. 